\title{
Insulin Requirements in Relation to Insulin Pump Indications in Type 1 Diabetes
}

\author{
Gabriela GHIMPET,EANU ${ }^{1 *}$, Silvia Ş. IANCU ${ }^{1,2}$, Gabriela ROMAN ${ }^{1,2}$, \\ Anca M. ALIONESCU ${ }^{2}$ \\ ${ }^{1}$ Iuliu Haţieganu'University of Medicine and Pharmacy Cluj-Napoca, Department ofDiabetes, Nutrition and Metabolic Diseases, 2-4 Clinicilor, Cluj-Napoca, \\ Romania;gabrielaghimpeteanu@yahoo.com ("correspondingauthor);groman@umfchij.ro; silviastefaniaiancu@gmail.com; scd@umfcluj.ro \\ ${ }^{2}$ Clinical Center ofDiabetes, Nutrition and Metabolic_Disorders, 2-4 Clinicilor, Cluj-Napoca,_Romania; anca_aly@yahoo.com
}

\begin{abstract}
The purpose of the current research was to assess changes in daily insulin requirements in type 1 diabetic patients transitioning from multiple daily injections (MDI) of insulin to continuous subcutaneous insulin infusion (CSII) using an external insulin pump, according to clinical indications for changing therapy. The charts of 70 patients with type 1 diabetes (T1D) initiating insulin pump therapy were retrospectively reviewed before CSII and after optimization of glycaemic profile with CSII during hospital admission. Daily insulin doses, basal/bolus distributions, dose changes during treatment transition and glycaemic outcomes with MDI and optimized CSII according to insulin pump indications were evaluated. Daily insulin doses were not significantly different among indication groups, with both MDI and CSII; likewise, the overall daily distribution of basal/rapid insulin ratio was similar, around 40/60. With optimized CSII, significant differences were found only in basal/bolus distribution in patients initiating CSII for recurrent hypoglycemia, who had a significantly lower basal $(6.4 \%$ lower $)$ and a complementary higher bolus requirement, compared to patients initiating CSII for HbAlc $\geq 8.5 \%$. At transition, basal insulin needs declined similarly in the high HbAlc and impractical/inflexible MDI groups by approximately $20 \%$, and up to $30 \%$ in the recurrent hypoglycaemia group; bolus doses decreased by $20 \%$ when the indication was high $\mathrm{HbAlc}$ and by approximately $15 \%$ for the other indications. Glycaemic control was significantly improved only in patients initiating CSII for high HbAlc $(\geq 8.5 \%)$. Insulin pump indication should be considered when starting T1D patients on CSII. These findings may support clinicians in decision making regarding insulin dose changes when initiating insulin pump therapy.
\end{abstract}

Keywords: basal rate, insulin dose, insulin infusion systems, external infusion pump, glycated haemoglobin

\section{Introduction}

The use of continuous subcutaneous insulin infusion (CSII) through an external insulin pump has been proven to be safe and effective in the treatment of type 1 diabetes (T1D), several studies demonstrated its superiority over multiple daily injections (MDI) therapy, in terms of glycaemic control, glucose variability, rate of hypoglycemia and quality of life (Jeitler et al., 2008; Pickup and Renard, 2008; Fatourechi et al., 2009; Bragd et al., 2010; Gimenez et al., 2010). Although insulin pump use has increased considerably in the past decades in the developed countries, it is still underused in developing regions, due to the cost burden for healthcare systems. Nevertheless, the transition from MDI to CSII is not clearly defined by guidelines and optimization of glycaemic control is often delayed, as insulin dose adjustments are required (Bode et al., 2002; Conrad et al., 2002).

When switching adults to CSII, the general recommendation is to reduce the MDI total daily dose by up to $25 \%$ (Bode, 2013), while in children, the pediatric consensus proposes a decrease in total pre-pump insulin dose by $10-20 \%$ (Phillip et al., 2007). Basically, different clinical trials reporting insulin dose changes in T1D patients transitioning from MDI to CSII, found either a higher reduction (30-36\%) (Ahern et al., 2002; Doyle et al., 2004), or no change in daily insulin requirements (Litton et al., 2002). Moreover, the basal and bolus insulin requirements have been reported to differ significantly in pediatric patients and adults, although basal/bolus ratio established for adults $(50 / 50)$ is usually also applied for children (Cemeroglu et al., 2013).

It is well known that insulin requirement depends on many factors, such as age, duration of diabetes, physical activity, time of day, etc (Chico et al., 2014). However, 
260

literature data regarding insulin dose changes when transitioning from MDI to CSII for different insulin pump indications are scarce. Identifying these changes for subgroups of type 1 patients could be helpful in attaining a faster optimization of blood glucose levels, to reach the desired $\mathrm{HbAlc}$ target.

The main objective of this study was to evaluate the changes in total, basal and bolus insulin requirements when switching T1D patients from MDI to CSII for different clinical reasons.

\section{Material and Methods}

\section{Selection and description of participants}

Medical records from type 1 diabetic patients transitioning from multiple daily injections to insulin pump therapy during hospital admission at the Clinical Center of Diabetes, Nutrition and Metabolic Diseases, Cluj-Napoca, Romania, between January 2002 and December 2011 were retrospectively analyzed. Inclusion criteria consisted of: T1D patients with at least one year diabetes duration and experience with MDI ( $\geq 4$ insulin injections/day) and selfmonitored blood glucose (SMBG) (for at least 4 times/day); patients fulfilling the criteria of the national insulin pump program of the Ministry of Health for a fully reimbursed permanent insulin pump and infusion sets: children and adults with T1D and failure of MDI treatment; T1D and pregnant women (Romanian National Insurance House, 2015) were referred from across different diabetes care settings throughout the country to the Diabetes Center in Cluj-Napoca to be hospitalized and started on an insulin pump.

Patients admitted in the Romanian national insulin pump program for T1D were divided into 3 groups according to the main indications for insulin pump therapy recommended by international diabetes professional societies: high $\mathrm{HbAlc} \geq 8.5 \%$ with MDI therapy, MDI treatment inappropriate or impractical or recurrent hypoglycaemia on MDI (Phillip et al., 2007; Pickup, 2012a; Grunberger et al., 2014). Exclusion criteria: pregnancy, medications affecting glucose levels (e.g. glucocorticoids) and other chronic comorbidities. Data were retrospectively collected during pre-pump MDI and with CSII after achieving a favourable glycaemic profile before hospital discharge.

\section{Ethical issues}

The study was conducted in accordance with the ethical principles for medical research involving human subjects stated in the revised Helsinki Declaration.

\section{Methods}

All patients scheduled to initiate CSII treatment have been admitted in the diabetes clinic for at least one week and enrolled in an intensive educational program for people beginning CSII, conducted by experienced diabetes specialists and diabetes educator nurses. Demographic, anthropometric and diabetes specific data were recorded.

\section{Technical information}

Long acting insulin analogs were stopped $24 \mathrm{~h}$ before the planned CSII initiation, and NPH insulin was used for overnight glycaemic control. Pumps used were: Accu-Check Spirit, Paradigm RT, Veo, Minimed 508 and all pumps were started on rapid-acting insulin analog.

Pre-pump total daily dose (TDD) was reduced by $20 \pm 5 \%$; $50 \%$ of this amount was used as basal rate in adults and $40 \%$ in children, and most patients started on the same hourly basal rate, except for night time hourly basal rate from 12:00 AM to 3:00 AM, which was 0.1 U/h lower or higher than the 3:00 AM-7:00 AM interval, depending on individual tendencies for night time hypoglycaemia; also, daytime hypoglycaemia-prone time intervals were covered by $0.1 \mathrm{U} / \mathrm{h}$ lower insulin doses. Basal rate adjustments were made based on $6 \mathrm{~h}$ fasting tests performed at successive time intervals, skipping one meal/day on separate days, during hospital admission. Daily adjustments of the basal rate were made according to hourly SMBG during daytime fasting tests and bedtime, respectively $3 \mathrm{AM}$ and $7 \mathrm{AM}$ blood glucose for the night time basal rate. If fasting was not possible (e.g. children), the $2 \mathrm{~h}$ postprandial and the next pre-meal values were considered for basal rate adjustment. An HbAlc target $\leq 7.5 \%$ was considered reasonable for all patients.

\section{Statistics}

Statistical analysis was performed using SPSS Statistics v.22 (IBM Corporation). Normal distribution of variable was tested using the Shapiro-Wilk test. Continuous data were expressed as mean \pm standard deviation and categorical variables as percentages. Student's $t$ test was used to compare quantitative variables that proved to be normally distributed. Groups were compared by one-way analysis of variance (ANOVA). Nonparametric tests were used to compare variables that proved not to have a normal distribution. Correlation between variables was assessed using Pearson's correlation analysis. Statistical significance was defined as $\mathrm{p}<0.05$ when two groups were compared and $\mathrm{p}<0.0167$ when three groups were compared.

\section{Results}

A total of 70 T1D patients were included in the study: mean age was $19.1 \pm 8.9$ years, while mean diabetes duration at pump start was $7.7 \pm 5.7$ years, $40 \%$ male and $88.5 \%$, from urban area. The proportions of patients on pre-pump basal insulin analog and rapid-acting analog were $92.8 \%$ and $98.5 \%$, respectively.

Patient distribution according to insulin pump indications was the following: Group 1 -high $\mathrm{HbAlc} \geq 8.5 \%$ with MDI therapy - 50\% (35 patients) of cases, Group 2 MDI treatment inappropriate or impractical, meaning 34.3\% (24 patients) and Group 3 - recurrent hypoglycaemia on MDI, representing $15.7 \%$ (11 patients). Patient baseline characteristics and MDI insulin requirements organized by insulin pump indications are presented in Table 1.

Kruskal-Wallis tests conducted to determine if there were differences in age or diabetes duration between the three groups, showed no significant differences $(p=0.74$ and 0.76 , respectively).

There were no significant differences in body mass index between the three groups (Kruskal-Wallis test, $\mathrm{p}=0.202$ ). A higher percentage of females was recommended to start on insulin pump for high HbAlc (62.9\%) or recurrent hypoglycaemia $(63.6 \%)$.

Baseline MDI HbAlc across the three different insulin pump indication classes was significantly different among the groups with ANOVA testing $(\mathrm{p}<0.0005)$, HbAlc decreasing 
Table 1. Patient baseline characteristics and MDI insulin doses according to insulin pump indication

\begin{tabular}{|c|c|c|c|}
\hline & \multicolumn{3}{|c|}{ Insulin pump indication } \\
\hline & High $\mathrm{HbAlc} \geq 8.5 \%$ with MDI & MDI inappropriate/impractical & Recurrent hypoglycaemia on MDI \\
\hline $\mathrm{N}$ & 35 & 24 & 11 \\
\hline Age (years) & $19.5 \pm 9.7$ & $19.4 \pm 8.1$ & $17.4 \pm 9$ \\
\hline Male (\%) & 37.1 & 45.8 & 36.4 \\
\hline Diabetes duration (years) & $7.9 \pm 5.1$ & $7.4 \pm 5.1$ & $8.2 \pm 8.5$ \\
\hline Weight (kg) & $56.5 \pm 19.1$ & $53.8 \pm 12.7$ & $48.8 \pm 15.7$ \\
\hline Height $(\mathrm{m})$ & $1.6 \pm 0.1$ & $1.6 \pm 0.1$ & $1.5 \pm 0.1$ \\
\hline $\mathrm{BMI}\left(\mathrm{kg} \mathrm{m}^{-2}\right)$ & $21.2 \pm 4.7$ & $20.3 \pm 3.5$ & $18.7 \pm 2.3$ \\
\hline MDI HbAlc (\%) & $9.6 \pm 1.0$ & $7.7 \pm 0.4$ & $6.6 \pm 0.3$ \\
\hline MDI total daily dose (U) & $45.7 \pm 15.3$ & $46.1 \pm 16.7$ & $40.9 \pm 16.9$ \\
\hline MDI TDD $\left(\mathrm{U} \mathrm{kg}^{-1}\right)$ & $0.8 \pm 0.2$ & $0.8 \pm 0.2$ & $0.8 \pm 0.2$ \\
\hline MDI bolus $\mathrm{U} \mathrm{kg}^{-1}$ & $0.4 \pm 0.1$ & $0.5 \pm 0.1$ & $0.5 \pm 0.1$ \\
\hline MDI basal $\mathrm{U} \mathrm{kg}^{-1}$ & $0.3 \pm 0.1$ & $0.3 \pm 0.1$ & $0.3 \pm 0.7$ \\
\hline MDI bolus/TDD (\%) & $58.2 \pm 9.3$ & $58.7 \pm 11.2$ & $59.4 \pm 9.6$ \\
\hline MDI basal/TDD (\%) & $41.8 \pm 9.3$ & $41.2 \pm 11.2$ & $40.5 \pm 9.6$ \\
\hline
\end{tabular}

Table 2. CSII insulin doses according to insulin pump indication

\begin{tabular}{|c|c|c|c|}
\hline & \multicolumn{3}{|c|}{ Insulin pump indication } \\
\hline & Group 1 & Group 2 & Group 3 \\
\hline CSII total daily dose (U) & $33.8 \pm 8.4$ & $35.7 \pm 8.7$ & $30.9 \pm 12.4$ \\
\hline CSII total daily dose $\left(\mathrm{U} \mathrm{kg}^{-1}\right)$ & $0.6 \pm 0.2$ & $0.6 \pm 0.1$ & $0.6 \pm 0.2$ \\
\hline CSII bolus $\mathrm{U} \mathrm{kg}^{-1}$ & $0.3 \pm 0.1$ & $0.4 \pm 0.1$ & $0.4 \pm 0.1$ \\
\hline CSII basal $\mathrm{U} \mathrm{kg}^{-1}$ & $0.2 \pm 0.0$ & $0.2 \pm 0.0$ & $0.2 \pm 0.0$ \\
\hline CSII bolus/TDD (\%) & $57.5 \pm 6.8$ & $60.9 \pm 8.8$ & $63.9 \pm 3.8$ \\
\hline CSII basal/TDD (\%) & $42.5 \pm 6.8$ & $39.1 \pm 8.8$ & $36.1 \pm 3.8$ \\
\hline
\end{tabular}

Data are presented as mean \pm standard deviation, unless otherwise stated. TDD- total daily dose; CSII- continuous subcutaneous insulin infusion

significantly from Group 1, to Group 2, to Group 3. Homogeneity of variances using Levene's test was violated. Games-Howell post-hoc analysis revealed that $\mathrm{HbA1c}$ decreased significantly $(\mathrm{p}<0.0005)$ from Group 1 to Group $2(-1.8 ; 95 \%$ CI (-2.3 to -1.3$))$, as well as from Group 1 to Group 3 (-2.9; 95\% CI (-3.4 to -2.5); $\mathrm{p}<0.0005)$. groups

Pre-pump insulin dose differences among pump indication

No statistically significant differences (ANOVA, p > 0.05) were found between the three groups regarding MDI doses (rapid, basal and total daily doses) used before starting on insulin pump. MDI insulin dose requirements are presented in Table 1.

Basal insulin requirement in the whole study group accounted for $41.4 \pm 9.9 \%$ of MDI daily totals. groups

Insulin pump dose differences among pump indication

CSII doses reached during adjustment to achieve a favourable glycaemic profile, according to insulin pump indication groups, are represented in Table 2.

There were no statistical differences between the three groups with regards to CSII total, bolus and basal insulin doses ( $\left.\mathrm{U} \mathrm{kg}^{-1}\right)$, except for basal/bolus ratios, which were significantly different among the groups. Basal requirement in the whole study group accounted for $40.3 \pm 7.5 \%$ of pump daily totals.

Basal insulin percentages across groups decreased from Group 1 to Group 2, to Group 3 (ANOVA), and the GamesHowell post-hoc analysis showed a significant decrease in basal insulin percentage $(\mathrm{p}=0.001)$ from Group 1 to Group 3 (6.4\%; 95\% CI (2.4 to 10.4$)$ ), and an equivalent significant increase in bolus percentage from Group 1 to Group 3 .
Insulin dose changes after transition from MDI to CSII according to indication

There was a strong positive correlation (Pearson correlations) between MDI and CSII total daily insulin doses $(\mathrm{r}=0.696, \mathrm{p}<0.0005)(\mathrm{U} \mathrm{kg}-1)$, bolus $(\mathrm{r}=0.589, \mathrm{p}<$ $0.0005)\left(\mathrm{U} \mathrm{kg}^{-1}\right)$ and basal $(\mathrm{r}=0.582, \mathrm{p}<0.0005)$ insulin $(\mathrm{U}$ $\left.\mathrm{kg}^{-1}\right)$ needed. Linear regression analysis established that each of the pre-pump insulin doses (total, basal and prandial insulin doses) could statistically predict CSII corresponding insulin doses; pre-pump total, basal and prandial requirements accounted for $47.7 \%, 32.9 \%$ and $33.7 \%$ of the explained variability in CSII total, basal and prandial insulin doses, respectively.

All insulin requirements decreased when transitioning from MDI to CSII: total daily insulin dose $/ \mathrm{kg}$ decreased to $78.3 \pm 15.6 \%$, bolus $/ \mathrm{kg} /$ day decreased to $82.2 \pm 23.7 \%$ and basal $/ \mathrm{kg} /$ day decreased to $79.4 \pm 26.4 \%$ of the previous MDI doses, with no significant differences among the indication groups.

When indication groups were analyzed separately, paired samples t-tests indicated statistically significant reductions in all insulin requirements when transitioning from MDI to insulin pump (Fig. 1); overall mean reductions of 0.19 ((95\% CI, 0.091 to 0.180$\left.) \mathrm{U} \mathrm{kg}^{-1}, \mathrm{p}<0.0005\right)$ in total daily dose, of 0.08 ((95\% CI, 0.091 to 0.10$) \mathrm{U}$ kg-1, p < 0.0005) in basal and of 0.10 ((95\% CI, 0.06 to 0.10$\left.) \mathrm{U} \mathrm{kg}^{-1}, \mathrm{p}<0.0005\right)$ in bolus requirements were found.

\section{HbAlc at 3 months and insulin pump indications}

Median HbAlc values achieved at 3 months were the highest in Group 1 (8.0\%; IQR (interquartile range) 7.0-9.0), while the lower values were in Group 3 (6.6\%, IQR 5.8-7.4) and 7.6\%, IQR 6.8-8.4 in Group 2. 


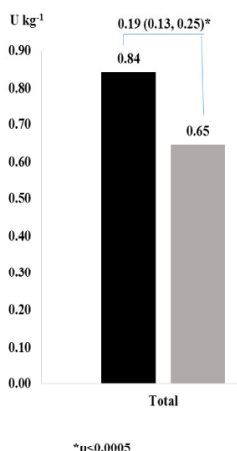
"

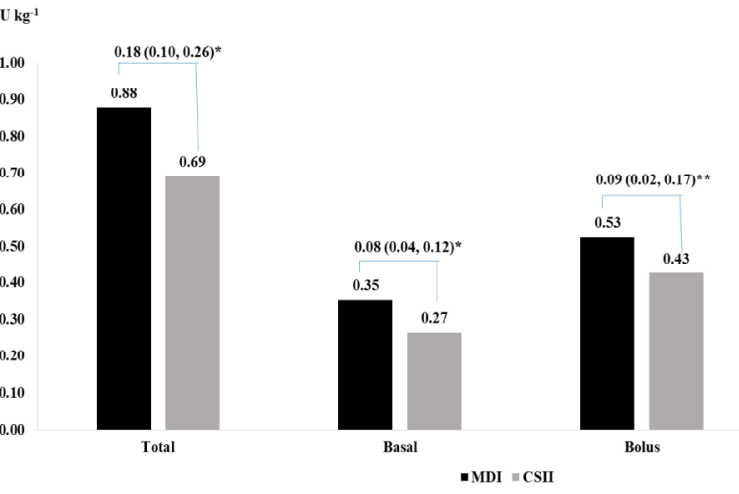

${ }^{*} \mathrm{p}=0.0001 ; *{ }^{*} \mathrm{p}=0.0158$

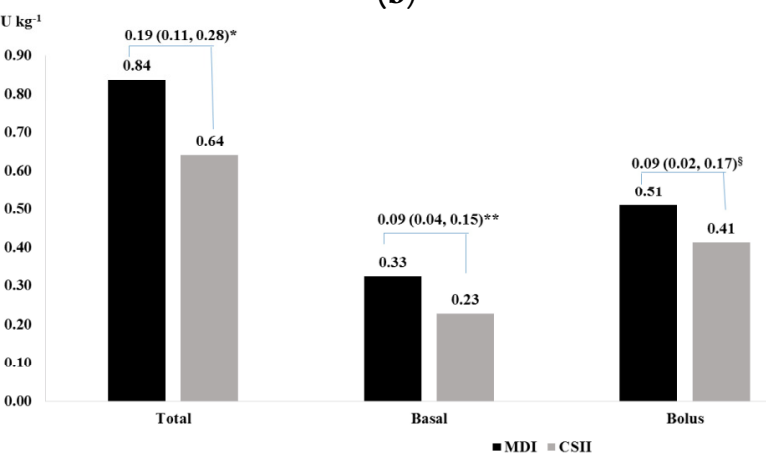

(b)

(c)

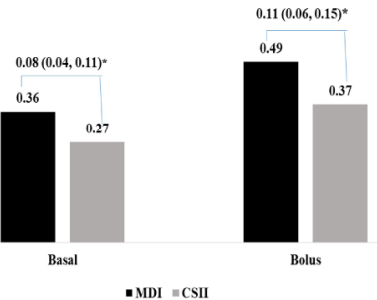

(a)

Fig. 1(a) MDI to CSII insulin dose change in patients with high HbAlc $\geq 8.5 \%$ pump indication; (b) MDI to CSII insulin dose change in patients with inappropriate/ impractical MDI insulin pump indication; (c) MDI to CSII insulin dose change in patients with recurrent hypoglycaemia insulin pump indication; $\mathrm{p}$ values according to paired $\mathrm{t}$-test

A Kruskal-Wallis test was conducted to determine if there were differences in $\mathrm{HbAlc}$ values achieved at 3 months between groups that differed in their insulin pump indication, considering that the basal rate did not vary more than 5\%. Distributions of $\mathrm{HbAlc}$ values were not similar for all groups, as assessed by visual inspection of boxplots. The distributions of $\mathrm{HbAlc}$ values were statistically significantly different between the indication groups, $\chi^{2}(2)=22.842, \mathrm{p}<0.0005$.

Subsequently, pairwise comparisons were performed using Dunn's procedure with a Bonferroni correction for multiple comparisons. This post hoc analysis revealed statistically significant differences in $\mathrm{HbAlc}$ values between Group 3 $($ mean rank $=11.73)$ and Group $2($ mean rank $=32.83),(\mathrm{p}=$ 0.013 ), and respectively between Group 3 and Group 1(mean rank $=44.80),(p<0.0005)$, but not between Group 1 and Group 2.

Patients in Group 1 experienced a significant reduction in median $\mathrm{HbAlc}$ value (1\% reduction), after the initiation of insulin pump therapy at 3 months (8\%) versus baseline (9.2\%), as assessed by Wilcoxon signed-rank test $(p<0.0005)$. No statistically significant reductions in $\mathrm{HbAlc}$ were found in the other treatment indication groups.

\section{Discussion}

The hereby retrospective study described three groups of young T1D patients transitioning from MDI to insulin pump therapy for different indications. The most frequent reason for changing treatment was the high HbAlc (in half of the patients under study), followed by the inappropriate/impractical use of MDI (34.3\%).

During MDI treatment, no differences in daily insulin doses were found among groups; the basal/bolus ratios used during MDI in the three groups were similar among indications.

After switching to CSII and optimizing insulin profile, there were still no significant differences among the indication groups with regards to total, basal and bolus insulin requirements. The basal rate totalled about $42 \%$ of daily dose in the high HbAlc patients, and was lower in the other two indication groups. However, significant differences were found only in basal/bolus distribution for patients initiating CSII for recurrent hypoglycaemia, who had a significantly lower basal (6.4\% lower) and a complementary higher bolus requirement, compared to patients initiating CSII for high HbAlc. The rapid/basal insulin ratios found in the young population under study was in line with findings from other studies in prepubertal, peripubertal and postpubertal patients, the basal insulin percentage rarely reaching the adult level of $50 \%$, and usually ranging from $30-45 \%$ in these age groups (Conrad et al, 2002; Danne et al., 2006; Phillip et al., 2007; King, 2010; Cemeroglu et al., 2013).

Switching patients from MDI to CSII led to a total daily insulin dose decrease of $22 \%$; basal insulin requirements declined similarly in the high HbAlc and impractical/inflexible MDI groups by approximately $20 \%$, and slightly higher, up to $30 \%$, in the recurrent hypoglycaemia group; bolus doses decreased by $20 \%$ when the indication was high $\mathrm{HbAlc}$ and by approximately $15 \%$ for the other indications. All insulin requirements decreased significantly with CSII versus MDI. These findings are similar to the study conducted by Nicolajsen (2012) in a somewhat younger age group, $13.1 \pm 3.9$ years, also studied for different pump indications.

After all insulin dose adjustments with CSII and optimization of glycaemic control in all indication groups, the glycaemic outcomes at 3 months post-transition to CSII were significantly better in the high HbAlc indication group (1\% HbAlc reduction) versus the other two clinical indications, which was in agreement with the results published by other studies. Both meta-regression of mean HbAlc levels from conducted trials and data from individual patients showed that the greatest reduction in HbAlc levels with CSII occurred in 
those patients with the highest $\mathrm{HbAlc}$ level on MDI at baseline. There is the assumption that when quality of life improvements are taken into account along with reductions in HbAlc level, CSII is cost-effective when HbAlc levels on MDI are $\geq 8.5 \%$ (Pickup, 2012b).

\section{Conclusions}

When transitioning from MDI to CSII, insulin pump indication has to be considered in order to enhance pump bolus/basal insulin distributions in pre, peri and postpubertal T1D patients. This may be useful in reshuffling daily insulin requirements directly to optimized patient needs when transitioning to an insulin pump in clinical practice. Results from the present study support that the best outcomes are in patients initiating CSII for a high $\mathrm{HbAlc} \mathrm{indication.}$

The main limitations of the current study are related to the retrospective nature of the observation, as well as to the small number of patients included in the CSII indication groups.

\section{References}

Ahern JA, Boland EA, Doane R, Ahern JJ, Rose P, Vincent M, Tamborlane WV (2002). Insulin pump therapy in pediatrics: a therapeutic alternative to safely lower $\mathrm{HbAlc}$ levels across all age groups. Pediatric Diabetes 3(1):10-15.

Bode BW, Tamborlane WV, Davidson PC (2002). Insulin pump therapy in the 21st century. Strategies for successful use in adults, adolescents, and children with diabetes. Postgraduate Medicine 111(5):69-77.

Bode BW, Kyllo J, Kaufman FR (2013). Pumping protocol: A guide to insulin pump initiation. Medtronic Medical Education Academia, Northridge, USA.

Bragd J, von Dobeln A, Lins PE, Adamson U, Bergstrom J, Oskarsson P (2010). Basal insulin substitution with glargine or continuous subcutaneous insulin infusion in adult type 1 diabetes patients-a randomized controlled trial. Diabetes Technology and Therapeutics 12(9):689-693.

Cemeroglu AP, Thomas JP, Zande LT, Nguyen NT, Wood MA, Kleis L, Davis AT (2013). Basal and bolus insulin requirements in children, adolescents, and young adults with type 1 diabetes mellitus on continuous subcutaneous insulin infusion (CSII): effects of age and puberty. Endocrine Practice 19(5):805-811.

Chico A, Tundidor D, Jordana L, Saigi I, Maria MA, Corcoy R, Leiva $\mathrm{AD}$ (2014). Changes in insulin requirements from the onset of continuous subcutaneous insulin infusion (CSII) until optimization of glycemic control. Journal of Diabetes Science and Technology 8(2):371-377.

Conrad SC, McGrath MT, Gitelman SE (2002). Transition from multiple daily injections to continuous subcutaneous insulin infusion in type 1 diabetes mellitus. Journal of Pediatrics 140(2):235-240.

Danne T, von Schutz W, Lange K, Nestoris C, Datz N, Kordonouri O (2006). Current practice of insulin pump therapy in children and adolescents - the Hannover recipe. Pediatric Diabetes 7(Suppl 4):25-31.

Doyle EA, Weinzimer SA, Steffen AT, Ahern JA, Vincent M,
Tamborlane WV (2004). A randomized, prospective trial comparing the efficacy of continuous subcutaneous insulin infusion with multiple daily injections using insulin glargine. Diabetes Care 27(7):1554-1558.

Fatourechi MM, Kudva YC, Murad MH, Elamin MB, Tabini CC, Montori VM (2009). Clinical review: Hypoglycemia with intensive insulin therapy: a systematic review and meta-analyses of randomized trials of continuous subcutaneous insulin infusion versus multiple daily injections. Journal of Clinical Endocrinology and Metabolism 94(3):729-740.

Gimenez M, Lara M, Conget I (2010). Sustained efficacy of continuous subcutaneous insulin infusion in type 1 diabetes subjects with recurrent non-severe and severe hypoglycemia and hypoglycemia unawareness: a pilot study. Diabetes Technology and Therapeutics 12(7):517-521.

Grunberger G, Abelseth JM, Bailey TS, Bode BW, Handelsman Y, Hellman R, ... Rothermel C (2014). Consensus statement by the American association of clinical endocrinologists/American college of endocrinology insulin pump management task force. Endocrine Practice 20(5):463-489.

Jeitler K, Horvath K, Berghold A, Gratzer TW, Neeser K, Pieber TR, Siebenhofer A (2008). Continuous subcutaneous insulin infusion versus multiple daily insulin injections in patients with diabetes mellitus: systematic review and meta-analysis. Diabetologia 51(6):941-951.

King $A B$ (2010). How much do I give? Reevaluation of insulin dosing estimation formulas using continuous glucose monitoring. Endocrine Practice 16(3):428-432.

Litton J, Rice A, Friedman N, Oden J, Lee MM, Freemark M (2002). Insulin pump therapy in toddlers and preschool children with type 1 diabetes mellitus. Journal of Pediatrics 141(4):490-495.

Nicolajsen T, Samuelsson A, Hanas R (2012). Insulin doses before and one year after pump start: children have a reversed dawn phenomenon. Journal of Diabetes Science and Technology 6(3):589-594.

Phillip M, Battelino T, Rodriguez H, Danne T, Kaufman F (2007). Use of insulin pump therapy in the pediatric age-group: consensus statement from the European Society for Paediatric Endocrinology, the Lawson Wilkins Pediatric Endocrine Society, and the International Society for Pediatric and Adolescent Diabetes, endorsed by the American Diabetes Association and the European Association for the Study of Diabetes. Diabetes Care 30(6):16531662.

Pickup JC, Renard E (2008). Long-acting insulin analogs versus insulin pump therapy for the treatment of type 1 and type 2 diabetes. Diabetes Care 31(Suppl 2):S140-S145.

Pickup JC (2012a). Insulin-pump therapy for type 1 diabetes mellitus. New England Journal of Medicine 366(17):1616-1624.

Pickup JC (2012b). Management of diabetes mellitus: is the pump mightier than the pen? Nature Reviews Endocrinology 8(7):425433.

Romanian National Insurance House (2015). Romanian National Program for Diabetes Mellitus. Retrieved 2015 June 30 from http://www.cnas.ro/page/programul-national-de-diabetzaharat.html. 